\title{
Paleoetnobotânica dos macrorestos vegetais do tipo trançados de fibras encontrados no sambaqui Cubatão I, Joinville - SC
}

\author{
Sarah Petrykowski Peixe* \\ João Carlos Ferreira de Melo Jr** \\ Dione da Rocha Bandeira **
}

PEIXE, S.P.; MELO JR., J.C.F.; BANDEIRA, D.R. Paleoetnobotânica dos macrorestos vegetais do tipo trançados de fibras encontrados no sambaqui Cubatão I, Joinville - SC. Revista do Museu de Arqueologia e Etnologia, São Paulo, 17: 211-222, 2007.

Resumo: Trabalhos com testemunhos biológicos têm se tornado uma grande ferramenta para o entendimento do modo de vida de populações pretéritas. $\bigcirc$ presente estudo objetiva identificar taxonomicamente as espécies vegetais utilizadas preteritamente e classificadas como artefatos de origem fibrosa. Os artefatos foram coletados em perfil exposto do sítio, salvaguardados no acervo do Museu Arqueológico de Sambaqui de Joinville (MASJ), analisados por métodos padrões de anatomia vegetal e identificados por comparação com coleção de referência da flora atual do entorno do sítio arqueológico. As fibras foram identificadas como pertencentes a plantas do gênero Philodendron (Araceae), as quais são conhecidas popularmente por cipós e podem ter tido diversos usos. A ocorrência desses vegetais no sítio arqueológico sugere a presença de florestas circundantes e condições paleoecológicas similares às atuais.

Palavras-chave: Sambaqui - Paleoetnobotânica - Fibras vegetais - Anatomia vegetal - Araceae - Philodendron.

\section{Introdução}

\section{Estudos paleoetnobotânicos}

estudo de populações passadas é uma importante fonte de informações sobre a relação entre as sociedades

(*) Graduanda do Curso de Ciências Biológicas da Universidade da Região de Joinville - UNIVILLE. sarinha.pp@gmail.com $\left.{ }^{* *}\right)$ Depto. de Ciências Biológicas da Universidade da Região de Joinville - UNIVILLE. joao.melo@univille.net $\left.{ }^{* * *}\right)$ Museu Arqueológico de Sambaqui de Joinville MASJ.dione_bandeira@terra.com.br humanas e o meio ambiente. Revela também como elas se apropriavam e faziam uso dos recursos naturais disponíveis (Ceccantini 2001).

Neste sentido, a Paleoetnobotânica é uma poderosa ferramenta para a reconstrução de culturas passadas, examinando a interação de populações humanas com plantas (Hastorf \& Popper 1988; Pearsall 2000; Amorozo et al. 2002). A análise do material vegetal inclui o estudo desta flora diretamente coletada e usada pelo ser humano (Vernet 1990).

No Brasil ainda não existe uma forte interação entre a Arqueologia e a Botânica e 
são poucos os trabalhos de Paleoetnobotânica ou Arqueobotânica já produzidos. Isto possivelmente está relacionado à escassez de materiais vegetais bem preservados em sítios arqueológicos brasileiros ou à falta de interesse dos pesquisadores em estudos no ramo arqueobotânico, como apontam Ceccantini \& Gussella (2001).

Estudos antracológicos realizados por Scheel-Ybert $(2000,2001)$ em sambaquis do litoral dos estados do Rio de Janeiro e de Santa Catarina são pioneiros na arqueologia brasileira. Fibras e madeiras não carbonizadas foram objetos de estudo em abrigos sob rocha apenas recentemente (Ceccantini \& Gussela 2001; Fernandez 2003).

Fazendo-se uma relação entre o acima exposto e a produção científica sobre os sambaquis encontrados na zona costeira de $\mathrm{SC}$, trabalhos que consideram em suas análises o testemunho de origem vegetal são praticamente inexistentes.

Ainda que existam registros da ocorrência de vestígios vegetais em sambaquis, a exemplo dos sítios Espinheiros II (Benz 2000) e Cubatão I (Oliveira \& Hoenicke 1994) em Joinville-Santa Catarina, a maior parte da investigação do modo de vida da população sambaquiana baseia-se principalmente na cultura material representada por vestígios faunísticos, esqueletais humanos e artefatos desses povos (Beck 1972 e 1973; Figuti s/d a e s/d b; Tiburtius 1996; Bibow 1997; Bandeira 1992 e 2004). Isso revela a necessidade de estudos específicos acerca dos vestígios vegetais encontrados nos sítios da região.

\section{Sambaquis}

O litoral brasileiro teve a sua ocupação humana muito anterior à chegada dos primeiros europeus. Esses ocupantes mais antigos marcaram sua presença por construir colinas artificiais de dimensões variadas, cuja composição chega a $80 \%$ de conchas de moluscos bivalves, além de enterramentos humanos, artefatos, ossos e dentes, as quais são conhecidas como sambaquis (Figuti s.d.b; Bandeira 2005).
As populações construtoras desses depósitos residiram em planícies fluvio-lagunares holocênicas, próximas aos manguezais, lagoas e estuários (Oliveira 1998). Os sambaquis apresentam datações variáveis, sendo os registros mais antigos de ocupação em torno de 6.500 A.P (Gaspar 2000).

Conforme apontam Afonso \& De Blasis (1994), os estudos realizados para elucidar a cultura dessas comunidades incluem análises sedimentológicas, estratigráficas, esqueletais, entre outras, fornecendo dados sobre os vestígios preservados nas camadas de deposição.

A maioria das informações sobre estas sociedades é produzida pela Arqueologia, através do estudo de remanescentes materiais (Bandeira 2005). Assim, o que inicialmente era considerado um fenômeno natural, e posteriormente um local de descarte de restos de cozinha de coletores é, atualmente, definido como o resultado de ordenado trabalho social para construir um imponente marco paisagístico (Gaspar 2000).

As pesquisas de campo em sambaquis obtêm grande quantidade de materiais e dados que podem levar a um entendimento sobre os hábitos desses povos (Afonso \& De Blasis 1994). É fato que a obtenção de alimento ocorria através da coleta, caça e pesca, embora se acredite que essas populações usavam o recurso da horticultura (Beck 1973). Ainda que os vestígios orgânicos preservados nas camadas dos sítios pareçam demonstrar que a base alimentar desses indivíduos eram os moluscos por sua freqüência e cuja formação calcária ficou preservada por um longo tempo, outros estudos têm demonstrado o contrário (Beck 1972).

A coleta de vegetais também foi uma forma de obter matéria-prima para a confecção de artefatos possivelmente utilizados na forma de nós, trançados e amarrações, e não apenas para alimentos (Bandeira 1992).

Esta pesquisa foi desenvolvida tendo como objetivo identificar através de técnicas de anatomia vegetal interpretações arqueobotânicas e paleoetnológicas a partir de vestígios vegetais encontrados no sítio arqueológico Cubatão I no município de Joinville, Santa Catarina. 


\section{Material e Métodos}

Área de estudo

O Sítio Arqueológico Sambaqui Cubatão I está situado na área rural do município de Joinville, Santa Catarina, na fazenda Trevo, nas coordenadas 26¹2'15,0"S e 4846'19,0"W, à margem direita do Rio Cubatão, próximo de sua foz (Gonçalves et al. 2006) (Fig. 1). O acesso rodoviário é dado pela estrada Cubatão Grande (Oliveira \& Hoenicke 1994).

A bacia hidrográfica do Rio Cubatão é a maior e mais importante do complexo hídrico da Baía da Babitonga (Knie 2002), abrangendo os municípios de Joinville e Garuva, com afluentes nascendo na Serra do Mar (Gonçalves et al. 2006).

A vegetação original do entorno encontrase praticamente destruída pelo povoamento histórico da região (Oliveira \& Hoenicke 1994; Gonçalves et al. 2006). No entanto, podem-se perceber remanescentes de manguezal e floresta ombrófila densa com indivíduos predominantemente arbóreos com grande heterogeneidade (Knie 2002, Gonçalves et al. 2006).

Este ambiente é uma área sujeita às inundações por apresentar principalmente

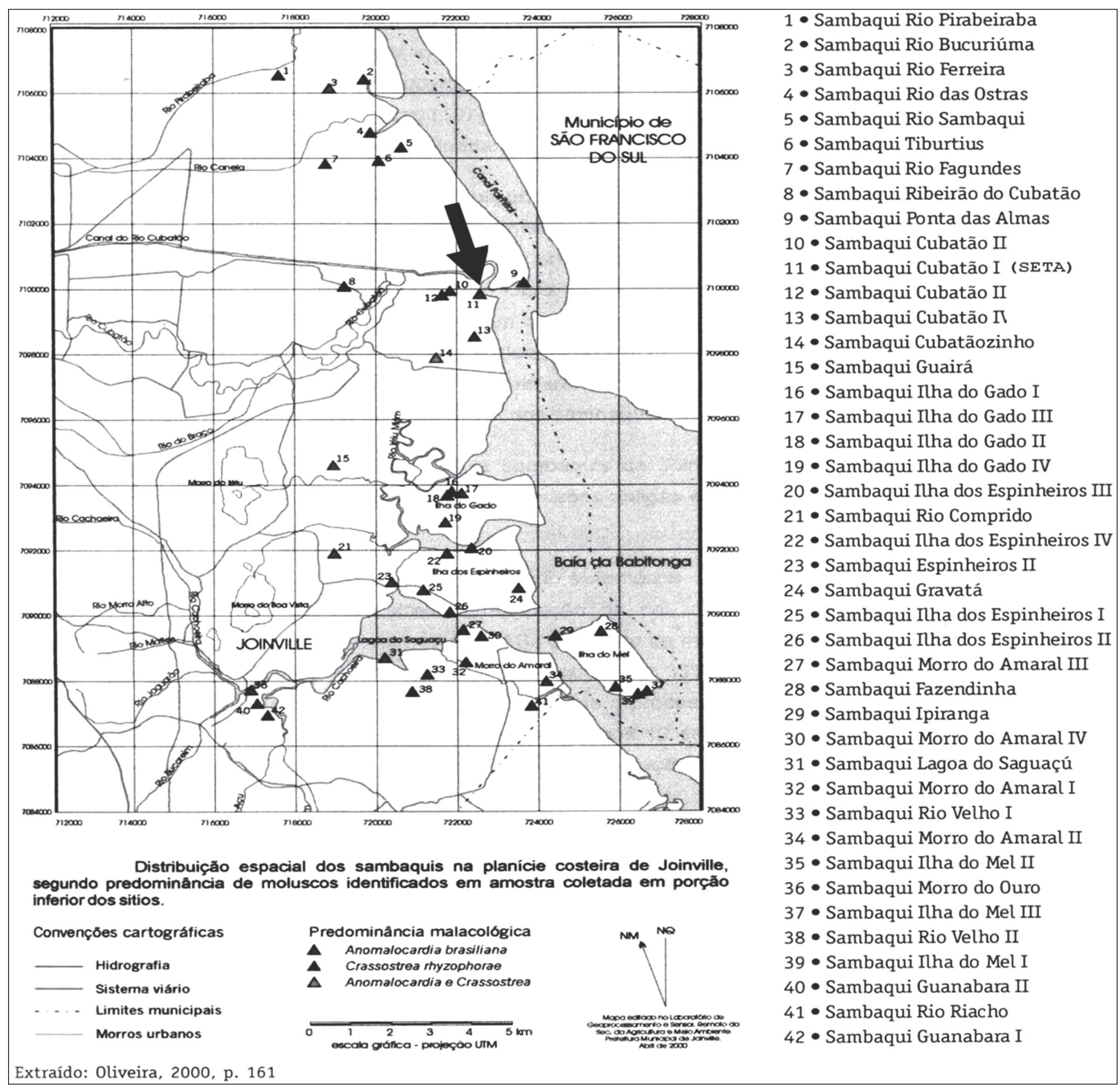

Fig. 1. Distribuição espacial dos sambaquis na planície costeira de Joinville. Sambaqui Cubatão I (seta). 
Paleoetnobotânica dos macrorestos vegetais do tipo trançados de fibras encontrados no sambaqui Cubatão I, Joinville - SC. Revista do Museu de Arqueologia e Etnologia, São Paulo, 17: 211-222, 2007.

manguezais, sucedidos por restinga, vegetações de encosta e de planície (Knie 2002). A formação florestal latifoliada está relacionada aos altos índices pluviométricos do local. Estas condições ambientais favorecem o desenvolvimento de uma diversidade vegetal com alto volume de biomassa, sendo propício ao aparecimento de epífitas e lianas lenhosas.

\section{Material arqueobotânico}

O material arqueológico estudado foi obtido no acervo do Museu Arqueológico de Sambaqui de Joinville (MASJ) e em coletas in situ. Foram realizadas coletas não sistemáticas, na forma de salvamento no perfil leste do sítio, aproveitando o material exposto pelo processo de erosão fluvial, cujo registro de localização se deu em contexto geral (Fig. 2 A, B, C e D). Observou-se que os materiais arqueológicos de origem vegetal classificados como fibras estavam presentes unicamente nas camadas estratigráficas inferiores do sítio, juntamente com outros tipos de testemunhos, a saber: carvões, fragmentos de madeira e frutos de palmeiras.
O material artefatual de origem vegetal coletado foi fixado em formaldeído $10 \%$, pois já se encontrava em condições de enxarcamento e transportado para o museu onde passou por procedimentos de curadoria.

\section{Coleção de referência}

A identificação de material vegetal de um sítio arqueológico requer a elaboração de uma coleção de referência que conte com amostras de material atual e literatura especializada para medidas comparativas (Hastorf \& Popper 1988).

Com base no levantamento florístico realizado em fragmento florestal do entorno do sambaqui em estudo, foi elaborada uma coleção de referência do lenho das espécies lianescentes.

As espécies coletadas foram prensadas com o auxílio de treliças para o transporte e herborizadas em laboratório conforme as recomendações propostas por Fidalgo \& Bononi (1989). As exsicatas foram tombadas no Herbário Joinvillea - UNIVILLE.

A coleção foi composta por dois elementos distintos: (1) conjunto de exsicatas; e (2)
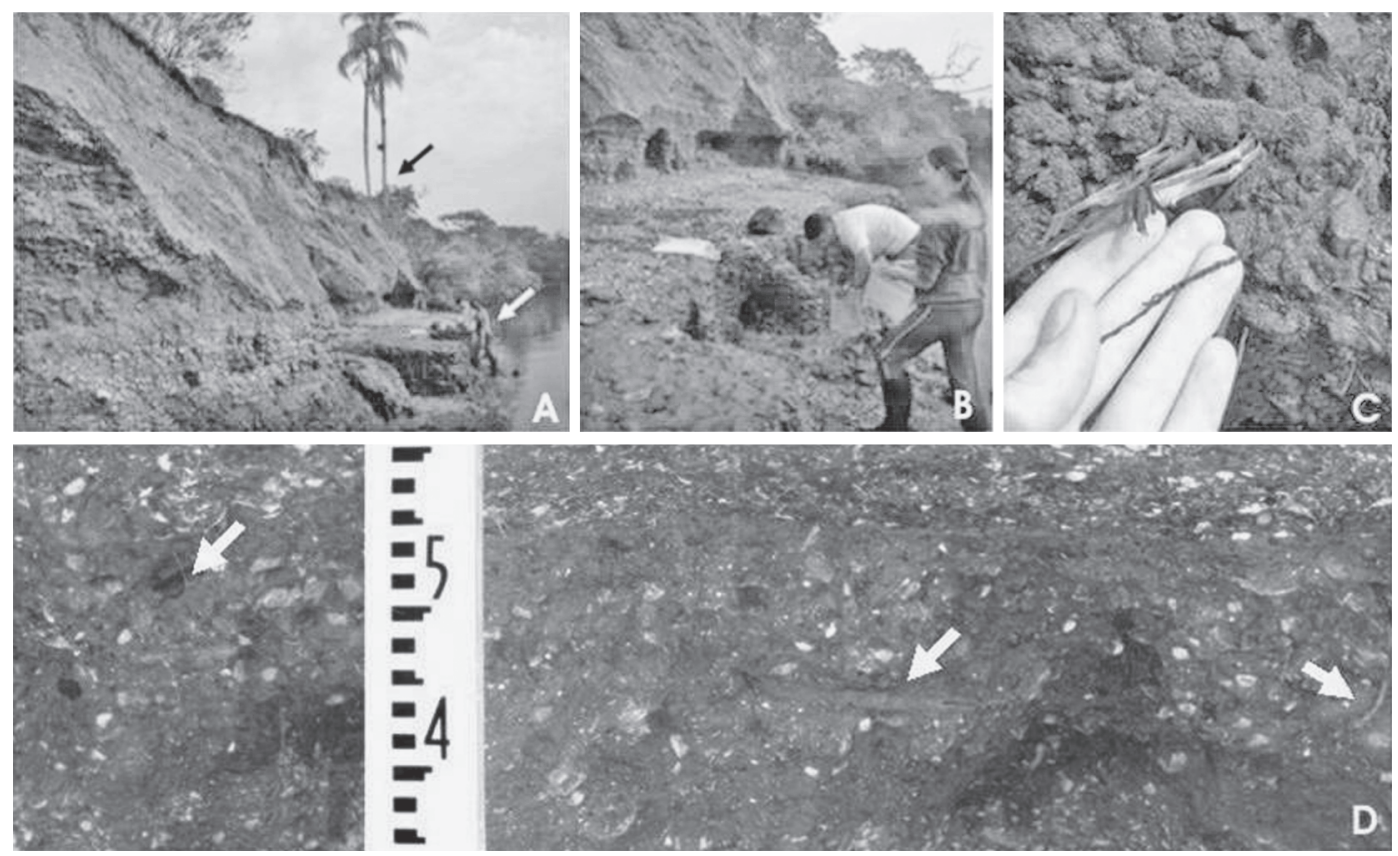

Fig. 2. Coleta do material arqueológico. A: vista do perfil de coleta; B: acondicionamento das amostras coletadas; C: trançados de fibras no sedimento arqueológico; D: vista detalhada do perfil e nível estratigráfico. 
conjunto de lâminas histológicas referentes às estruturas caulinares e/ou radiculares coletadas de cada espécie em campo.

\section{Preparações histológicas}

Foram produzidos cortes histológicos a mão livre tanto das amostras de lenho do material de referência quanto das amostras de material arqueológico. Os cortes histológicos foram feitos, com auxílio de navalha descartável, nas secções transversal, longitudinal tangencial e radial. No material arqueológico tais cortes foram realizados com o material sempre embebido em solução fixadora de forma a evitar, por dessecamento, a fragmentação do material. Em seguida foram lavados em água destilada. Os cortes foram clarificados em $\mathrm{NaClO} 14 \%$, corados com safranina $1 \%$ aquosa, desidratados em série alcoólica (50\% e 100\%) (Ceccantini 1997). As lâminas permanentes foram montadas com resina sintética Entelan. De ambos os materiais foram obtidos elementos celulares dissociados segundo o Método de Franklin modificado (Kraus \& Arduin 1997).

Desta forma, foram estudadas comparativamente as características anatômicas de caule e raiz das espécies da coleção de referência com as estruturas anatômicas obtidas em preparações histológicas do material arqueológico, a fim de se determinar o táxon ao qual pertence $(\mathrm{m}) \mathrm{a}(\mathrm{s})$ planta(s) encontrada(s) sob a forma de testemunho (trançados de fibras) no sítio arqueológico Cubatão I.

\section{Resultados e discussão}

\section{O material estudado}

A preservação de macro-restos vegetais em contexto arqueológico depende, dentre outros fatores, da resistência à decomposição microbiana (Hastorf \& Popper 1988). O fato de esses vegetais estarem tão bem conservados neste sítio está diretamente ligado à sua proximidade com o Rio Cubatão, e a umidade decorrente.

Os vestígios vegetais estudados encontramse em uma das camadas mais inferiores do sambaqui. Não foram observados trançados de fibras nas camadas superiores. Isto não indicaria necessariamente a ausência do uso de vegetais em fases posteriores de ocupação, mas talvez a não conservação desses materiais nos estratos superiores, caracteristicamente mais secos e de difícil contato com a água do rio, mesmo sob influência da maré alta.

Foram obtidas durante as coletas amostras de trançados, cordas, amarrações e nós que se encaixaram na categoria artefatos, por terem passado por processo de manufaturamento humano. Apesar disso, alguns itens coletados não apresentavam marcas de uso, desta forma foram nominados biofatos e considerados refugos de fabricação. Assim, houve uma seleção dos materiais a serem analisados, priorizando-se apenas os artefatos fibrosos passíveis de análise anatômica.

A amostra 1 (Fig. 3 A) foi caracterizada por ser um emaranhado de fibras laminadas unidas por um nó. Essas fibras foram encontradas em abundância nas camadas do sítio onde os vestígios vegetais estavam sendo evidenciados. A análise dos artefatos demonstrou que em alguns casos a matéria-prima foi trabalhada atentamente, sendo as fibras entretorcidas com três elementos na trama, armadas de forma eqüidistante e pegadas entre si, apresentando pequenos filetes de lianas dispostos verticalmente, mantendo a sua estrutura compacta, como é evidenciado na amostra 2 (Fig. 3 B). Um artefato de confecção semelhante, mas com maiores dimensões foi encontrado no acervo do MASJ (Fig. 4 D). Por estar seco não puderam ser realizados cortes histológicos, uma vez que a estrutura anatômica se encontrava comprometida.

Uma estrutura peculiar, mas de uso possível pelos sambaquianos que habitaram no sítio, foi a amostra 3 (Fig. 3 D), a qual apresenta dois galhos amarrados por fibras obtidas de cipós. Este tipo de procedimento pode ter sido empregado para fixar elementos construtivos do monte de conchas ou em estruturas de contenção.

As amostras 4 e 7 (Fig. 4 A e B) apresentam formato de corda trabalhada em três fibras longas torcidas entre si e amarradas em uma das extremidades com e sem nó na parte terminal. As amostras 5 e 6 (Figs. 4 C e D), diferindo unicamente em suas dimensões, 
Paleoetnobotânica dos macrorestos vegetais do tipo trançados de fibras encontrados no sambaqui Cubatão I, Joinville - SC. Revista do Museu de Arqueologia e Etnologia, São Paulo, 17: 211-222, 2007.
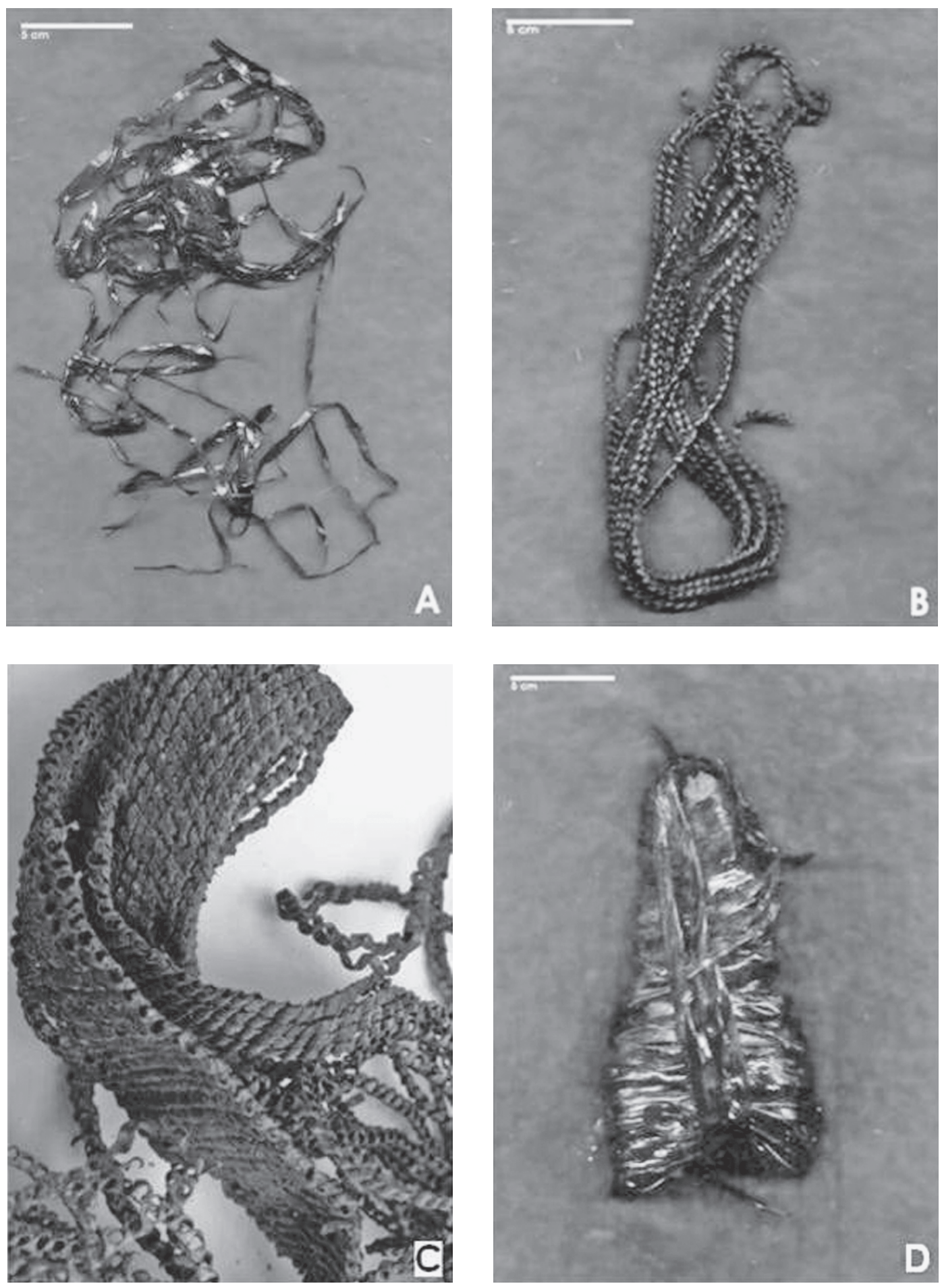

Fig. 3. Artefatos de fibras vegetais analisados anatomicamente. A: amostra 1, emaranhado com nó; B: amostra 2, trançado trabalhado; C: detalhe do artefato de fibra vegetal seco, presente no acervo do MASJ (não analisado anatomicamente); D: amostra 3, amarração. 

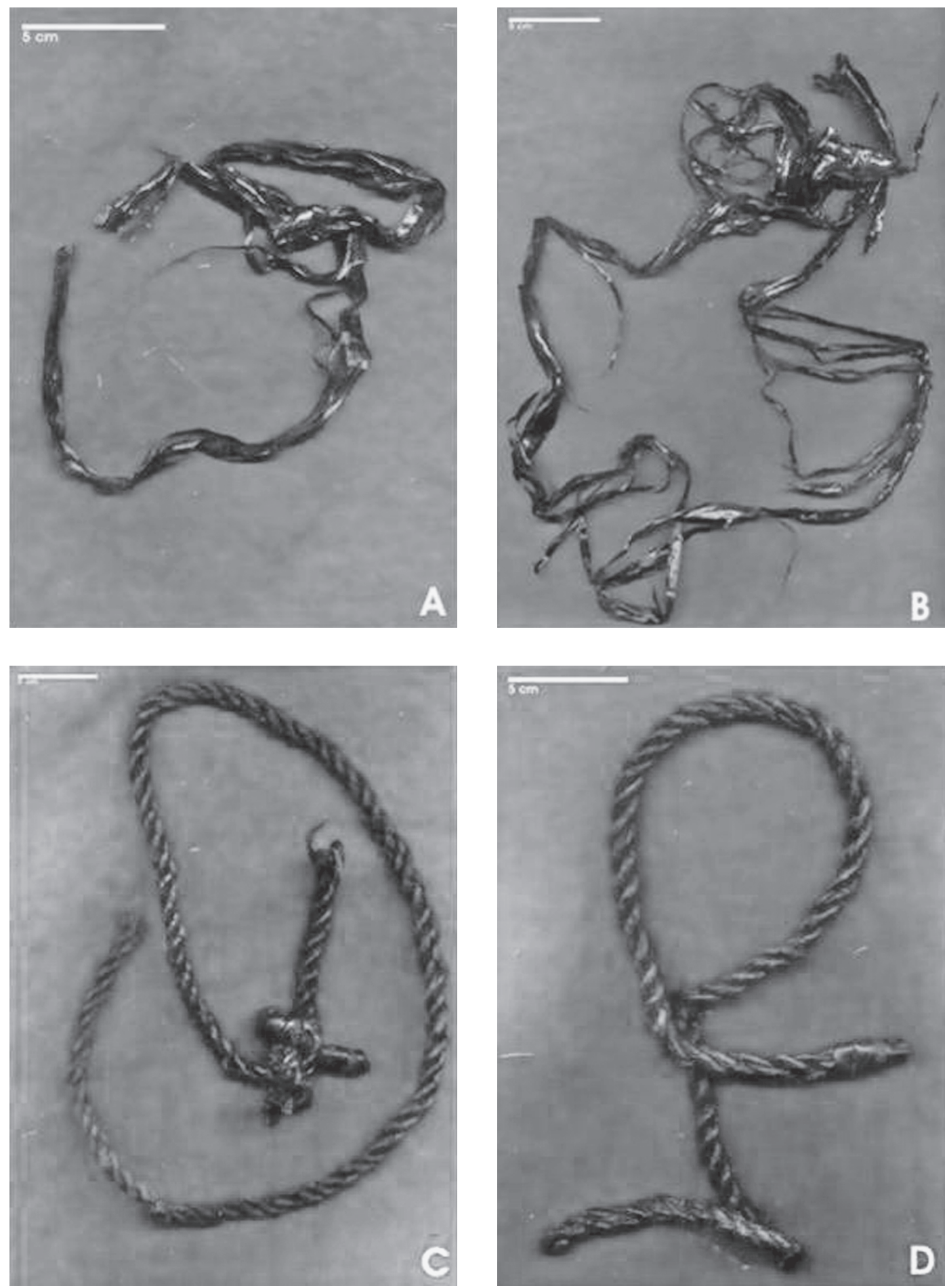

Fig. 4. Artefatos de fibras vegetais. A: amostra 5, pequeno nó; B: amostra 5, nó grande; C: amostra 7, corda com nó; D: amostra 4, corda. 
Paleoetnobotânica dos macrorestos vegetais do tipo trançados de fibras encontrados no sambaqui Cubatão I, Joinville - SC. Revista do Museu de Arqueologia e Etnologia, São Paulo, 17: 211-222, 2007.

apresentam fibras presas em um nó com um espaço circular que poderia enlaçar algum galho.

\section{Análise anatômica}

O excelente estado de preservação da estrutura interna desses vegetais no sítio permitiu que a maioria dos materiais coletados fosse preparada histologicamente, apresentando estruturas anatômicas bem conservadas. Não foi possível realizar outros cortes que não o transversal. A amostra desagregada em solução de Franklin não forneceu resultados passíveis de análise.

Desde o primeiro momento, havia a hipótese de que os materiais arqueológicos recuperados tivessem sido confeccionados em caules ou raízes de lianas, e não de folhas de palmáceas, outro material muito utilizado pelas populações pretéritas (Ribeiro 1986a). A confirmação desta hipótese ocorreu através da análise anatômica dos cortes transversais dos materiais estudados.

A análise anatômica demonstrou características típicas de Liliopsidas (monocotiledôneas), ou seja, a ausência de uma região cortical ou medular distinta. O cilindro vascular lobado possui elementos de vaso distribuídos aleatoriamente no tecido fundamental (Fig. 5 A). As células parenquimáticas são relativamente isodiamétricas e de paredes finas. Uma das características particulares do material foi a disposição de cordões, aparentemente, de floema ao redor dos elementos de vaso de grande diâmetro, formando uma estrutura estrelar anômala (Fig. 5 B), corroborando estudos feitos por Vianna, Soares \& Appezzatto-Da-Glória (2001). Todos os artefatos analisados apresentaram esta estrutura anatômica característica (Dahlgren et al. 1985).

Os materiais analisados são seguramente fragmentos de raiz e não apresentaram crescimento secundário. A estrutura anatômica observada assemelha-se às descrições estruturais de raízes escoras de P. bipinnatifidum Schott (Araceae) realizada por Vianna, Soares \& Appezzatto-Da-Glória (2001), as quais consideraram a estrutura lobada do cilindro vascular uma característica que permite a flexibilidade das raízes escora durante seu desenvolvimento.
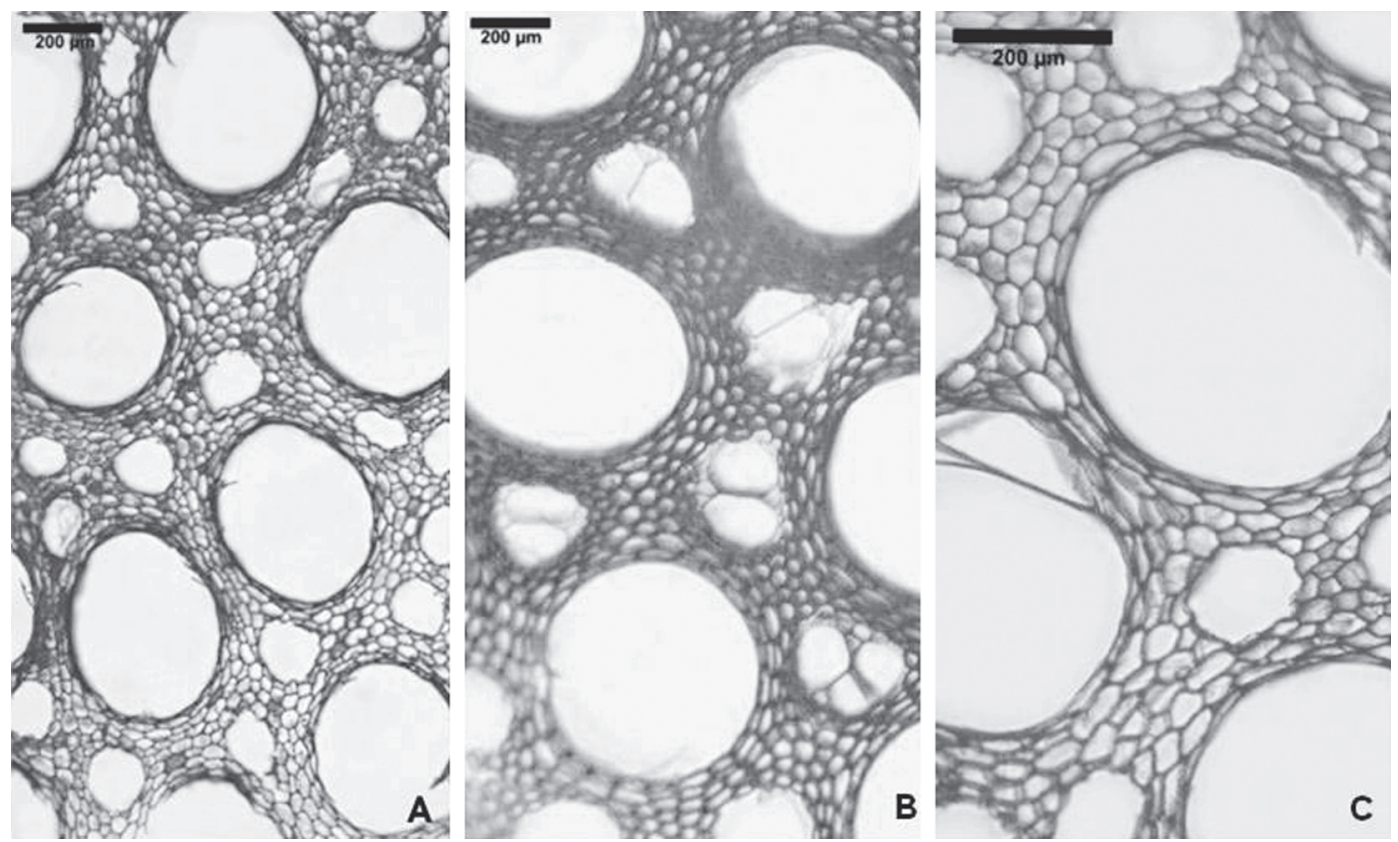

Fig. 5. Fotomicrografias dos materiais analisados anatomicamente evidenciando a similaridade das estruturas anatômicas observadas. A e C: material arqueológico; B: coleção de referência. 
A maioria dos vasos condutores nos cortes histológicos do material antigo se encontrava levemente deformada, o que pode ser explicado através das seguintes hipóteses:

- grande pressão exercida pelas camadas de sedimentos somada às condições físico-químicas do local, diretamente relacionada com o longo período em que o material ficou em meio às camadas estratigráficas do sítio arqueológico;

- deformação sofrida em virtude do trabalho humano com esse material.

Uma vez que todas as amostras arqueológicas obtidas e analisadas histologicamente mostraram padrões anatômicos semelhantes, infere-se que essas sejam provavelmente provenientes do mesmo material botânico.

Entre as amostras que compunham a coleção de referência coletada no entorno do sítio, houve uma que apresentou igual disposição das estruturas anatômicas (Fig. 5 C). Tal planta foi identificada taxonomicamente como Philodendron corcovadensis Schott 1829, perten- cente à família Araceae. Três tipos diferentes de Philodendron foram coletados, no entanto apenas um correspondeu às fibras dos materiais artefatuais (Fig. 6).

Araceae é uma família de monocotiledôneas cuja distribuição é cosmopolita, incluindo cerca de 100 gêneros e 3000 espécies, sendo que no Brasil ocorrem apenas 35 gêneros e 400 espécies (Souza \& Lorenzi 2005). Tais plantas habitam freqüentemente em áreas alagadas de regiões subtropicais e Floresta Ombrófila Densa.

Dentro desta família o gênero Philodendron é o segundo maior, sendo composto por até 500 espécies (Judd et al. 2002) A maioria das espécies deste gênero exibe uma grande variedade morfológica resultando em maior dificuldade na identificação, embora estas apresentem látex característico, folhas normalmente paralelas e flores unisexuadas (Hickey \& King 1997).

A identificação do material arqueológico em nível específico não pôde ser realizada, já que elementos necessários, como estruturas foliares e reprodutivas, não estavam presentes,

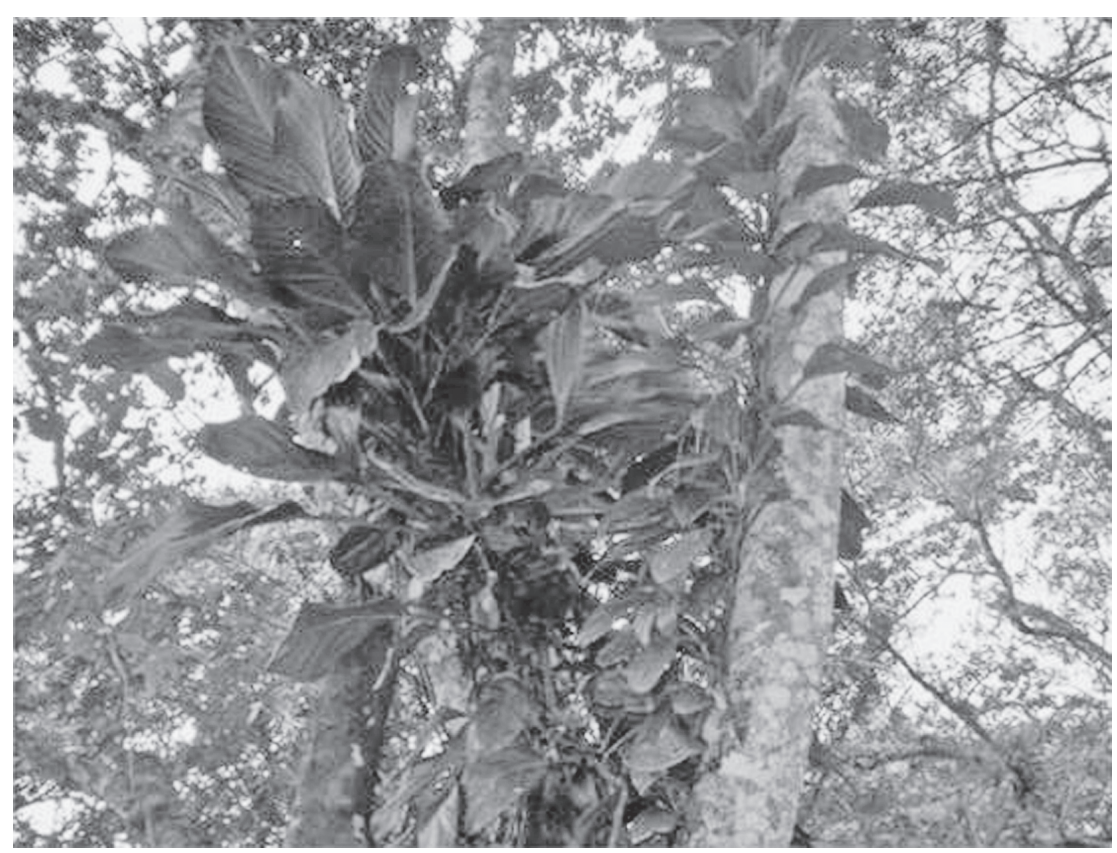

Fig. 6. Espécie de Philodendron encontrada no entorno do sítio cuja caracterização anatômica correspondeu à dos materiais arqueológicos. 
havendo neste caso apenas fragmentos de raiz. No entanto, com base nos estudos anatômicos comparativos, é possível afirmar que os artefatos feitos de vegetais no sítio Cubatão I pertencem ao gênero Philodendron.

\section{Interpretações etnobotânicas e etnoecológicas}

A maioria dos estudos paleoetnobotânicos tem voltado seu tema para a reconstituição da alimentação humana, porém, nem todas as plantas encontradas num sítio estão relacionadas à dieta (Hastorf \& Popper 1988). Esta pesquisa voltou-se para os vegetais utilizados sob a forma de artefatos pelos povos sambaquianos.

As funções desses materiais vegetais entre os povos sambaquianos, em comparação com os usos atribuídos pelas populações indígenas, mostram que as fibras vegetais foram comumente utilizadas na confecção de artefatos para as possíveis categorias: amarrar, atar, conter ou suportar (Ribeiro 1986b). Todas as amostras obtidas apresentaram alguma relação tecnológica e funcional com materiais utilizados pelos indígenas. Segundo Ribeiro (1986b), todos os grupos indígenas brasileiros empregam o cipó na técnica de amarração por enlace, tanto na construção de peças horizontais e verticais, como em casas, armadilhas e arcos.

Ribeiro (1986a) realizou um estudo com 72 tribos indigenas costeiras, analisando 960 peças; dessas, 37 foram fabricadas com materiais lianescentes. Dentre as espécies mais utilizadas, estavam o Philodendron imbe e Heteropsis jenmani para a confecção de armadilhas de peixes, cestos, cabos e cordas. Os padrões dos trançados variam conforme as tribos, mas nós eram muito freqüentes, bem como cordas torcidas.

A elevada quantidade de vestígios vegetais encontrados no sítio sugere a abundância de espécies de plantas nas redondezas dos sambaquis nos período de sua ocupação, sem que houvesse necessidade de longas buscas para a obtenção de matéria-prima. A presença de macro-restos vegetais do gênero Philodendron no sítio indica que as condições ecológicas e microclimáticas pretéritas, durante o período de ocupação deveriam ser muito semelhantes às atuais e que ocorriam formações florestais como as que ocorrem hoje.

\section{Considerações finais}

A presença marcante dos vestígios vegetais no Sambaqui Cubatão I, sob a forma de trançados de fibras, demonstra o conhecimento desses povos sobre a vegetação e o desenvolvimento de técnicas para sua utilização.

Os materiais arqueológicos de origem vegetal foram identificados como raízes adventícias de Philodendron (Araceae), planta atualmente comum no entorno do sítio.

As plantas deste gênero apresentam uso comum em amarrações pelas comunidades tradicionais atuais além de potencial medicinal, o que demonstra que esses mesmos recursos vegetais também podem ter sido explorados destas e de outras formas pelas populações que ali viveram no passado.

Do ponto de vista paleoecológico, a presença de macrorestos vegetais de Philodendron no Sambaqui Cubatão I sugere que, muito provavelmente, de forma semelhante ao que ocorre hoje na região, formações vegetacionais de florestas aluviais e restingas também tenham composto o cenário passado onde as populações sambaquianas que ali residiram desenvolveram saberes sobre determinadas plantas e o seu uso em suas atividades cotidianas.

\section{Agradecimentos}

À Universidade da Região de Joinville UNIVILLE, pelo suporte laboratorial prestado. Ao Museu Arqueológico de Sambaqui de Joinville - MASJ, pela disponibilização do material de estudo, infra-estrutura e apoio, em nome de toda a sua equipe técnico-científica. 
PEIXE, S.P.; MELO JR., J.C.F.; BANDEIRA, D.R. Paleoethnobotany of vegetal macroremains of the entangled fiber type found in the sambaqui Cubatão I, Joinville - Santa Catarina State. Revista do Museu de Arqueologia e Etnologia, São Paulo, 17: 211-222, 2007.

Abstract: Studies with biological testimonies have been a great tool to understand the way of life of past populations. The present study has as objective to identify taxonomically plant species used in the preterit and classified as fibrous artifacts. These artifacts were collected in exposed profile of the site, custodied in the collection of the Archaeological Museum of Sambaqui of Joinville (MASJ), analyzed by standard methods of plant anatomy and identified by comparison with reference collection of the current flora obtained in the archeological site surroundings. The fibers were identified as belonging to plants of the genera Philodendron (Araceae), which are known popularly as lianes. The occurrence of these plants at the archaeological site suggests the presence of surrounding forests and paleoecological conditions similar to our time.

Keywords: Shell mounds - Paleoethnobotany - Vegetal fibers - Plant anatomy - Araceae - Philodendron.

\section{Referências bibliográficas}

AFONSO, M. C.; DE BLASIS, P.A.D.

1994 Aspectos da Formação de um grande Sambaqui: Alguns indicadores em Espinheiros II, Joinville. Revista do Museu de Arqueologia e Etnologia, São Paulo, 4: 21-30.

AMOROZO, M.C.M.; MING, L.C.; SILVA, S.P. DA

2002 Métodos de coleta e análise de dados em etnobiologia, etnoecologia e disciplinas correlatadas. Rio Claro: Unesp.

BANDEIRA, D.R.

1992 Mudanças na estratégia de subsistência: O sítio arqueológico Enseada I - Um estudo de caso. Dissertação de Mestrado. Antropologia Social - UFSC, Florianópolis.

2004 Ceramistas Pré-coloniais da Baía da Babitonga, SC - Arqueologia e Etnicidade. Tese de Doutorado. Instituto de Filosofia e Ciências Humanas da Universidade Estadual de Campinas, Campinas - SP.

2005 Povos sambaquianos: Os construtores dos montes de conchas e os mais antigos moradores da Baía da Babitonga. Revista Joinville Ontem e Hoje, 4: 4-9.

BECK, A.

1972 A Variação do Conteúdo Cultural dos Sambaquis no Litoral de Santa Catarina.
Tese de Doutorado. Faculdade de Filosofia, Letras e Ciências Humanas UFSC, Florianópolis - SC.

1973 O Sambaqui de Enseada I - Um estudo de Tecnologia Pré-Histórica. Dissertação (Livre Docente). Universidade Federal de Santa Catarina, Florianópolis.

BENZ, D.M.

2000 Levantamento preliminar de algumas espécies de vertebrados pretéritos do Sítio Arqueológico Ilha dos Espinheiros II Joinville - SC. 56p. Trabalho de Conclusão de Curso (Graduação em Ciências Biológicas), Universidade da Região de Joinville - Univille, Joinville.

BIBOW, D.

1997 Análise do acervo malacológico pretérito do Museu Arqueológico de Sambaqui de Joinville - Santa Catarina. 71p. Trabalho de Conclusão de Curso (Graduação em Ciências Biológicas), Universidade da Região de Joinville - Univille, Joinville.

CECCANTINI, G.

1997 Cortes de Madeira em micrótomo de deslize. In: Kraus, J.E.; ARDUIN, M. (Eds.) Manual básico de métodos em morfologia vegetal. 
Seropédica, Edur, Apêndice III.: 125-128.

2001 O Uso de Indicadores Florísticos e Faunísticos em Arqueologia. Caderno de Pesquisa Ser. Bio., Santa Cruz do Sul, 13 (1): 47-56.

CECCANTINI, G.; GUSSELLA, L.W.

2001 Os Novelos de Fibras do Abrigo Rupestre Santa Elina (Jangada, MT, Brasil): Anatomia Vegetal e Paleoetnobotânica. Revista do Museu de Arqueologia e Etnologia, São Paulo, 11: 189-200.

DAHLGREN, R.M.T.; CLIFFORD H.T.; YEO P.F.

1985 The families of the monocotyledons: structure, evolution and taxonomy. Berlin: Springer.

\section{FERNANDEZ, M.H}

2003 Identificação dos Fragmentos de Madeira do Abrigo Rupestre de Santa Elina - MT. 51p. Trabalho de Conclusão de Curso (Ciências Biológicas) - Universidade Federal do Paraná, Curitiba.

FIDALGO, O.; BONONI, V.L.R.

1989 Técnicas de coleta, preservação e herborização de material botânico. São Paulo: Instituto de Botânica.

FIGUTI, L.

s/d a Estórias de um agropescador: A ictiofauna de sítios costeiros. mimeo

s/d b Zooarchaeology and Brazilian Shell-mounds, first steps. mimeo

GASPAR, M.D.

2000 Sambaqui: arqueologia do litoral brasileiro. Rio de Janeiro: Jorge Zahar Editor.

GONÇALVES, M.L.; ZANOTELLI, C.T.; OLIVEIRA, F.A. DE

2006 Diagnóstico e Prognóstico das Disponibilidades e Demandas Hidricas do Rio Cubatão do Norte - Joinville - Santa Catarina. Joinville: Editora Univille - SC.

HASTORF, C.A.; POPPER, V.S.

1988 Current Paleoethnobotany: Analytical Methods and Cultural Intrpretations of Archaeological Plant Remains. Chicago: The University of Chicago Press.

HICKEY, M.; KING, C.

1997 Common Families of flowering Plants. Cambridge: Cambridge University Press.

JUDD, W.S.; CAMPBELL, C.S.; KELLOGG, E.A.; STEYENS, P.F.; DONOGHUE, M.J.

2002 Plant Systematics: A phylogenetic approach. Massachusetts: Sinauer Associates.

KNIE, J.L.W.

2002 Atlas ambiental da região de Joinville: complexo hídrico da Baia da Babitonga. Joinville, SC: FATMA/GTZ.

KRAUS, J.E.; ARDUIN, M.

1997 Manual básico de métodos em morfologia vegetal. Edur: Seropédica.

OLIVEIRA, M.S.C.; HOENICKE, N.F.

1994 Sítios Arqueológicos em Joinville - SC: Inventário Descritivo Básico. Projeto 25: Museu Arqueológico de Sambaqui de Joinville, Fundação Instituto de Pesquisa e Planejamento Urbano de Joinville.

OLIVEIRA, M.S.C.

1998 Sambaquis em Joinville - SC: da Inserção Paleogeográfica à Problemática da Conservação In Situ. Especialização em Geografia - Universidade Federal de Santa Catarina, Florianópolis.

PEARSALL, D.M.

2000 Paleoethnobotany: a handbook of procedures. Orlando, Florida: Academic Press.

RIBEIRO, B.G.

1986a SUMA Etnológica Brasileira. Vol. 1, Petrópolis: Vozes.

1986b SUMA Etnológica Brasileira. Vol. 2, Petrópolis: Vozes.

SCHEEL-YBERT, R.

2000 Vegetation stability in the southeastern Brazilian coastal area from 5500 to $1400{ }^{14} \mathrm{C}$ yr BP deduced from charcoal analysis. Review of Paleobotany and Palynology, 110: 111-138.

2001 Vegetation stability in the Brazilian litoral during the late Holocene: anthracological evidence. Revista de Pesquisas em Geociências, 28 (2): 315-323.

SOUZA, V.C.; LORENZI, H

2005 Botânica sistemática: guia ilustrado para identificação das famílias de angiospermas da flora brasileira, baseado em APG II. Nova Odessa: Plantarum.

TIBURTIUS, G.A.E.

1996 Arquivos de Guilherme Tiburtius - Joinville: MASJ. Joinville - SC: Soluções.

VERNET, J.-L.

1990 Man and Vegetation in the Mediterranean area during the last 20,000 years. Netherlands: Kluwer Academic Publishers.

VIANNA, W.O.; SOARES, M.K.M.; APPEZZATO-

DA-GLÓRIA, B.

2001 Anatomia da raiz de escora de Philodendron bipinnatifidum (Schott) Araceae. Acta Botânica Brasílica, 15 (3): 313-320. 